\title{
Member Satisfaction Related to Self-Reported Cost Share and Difficulty in Obtaining Prescription Drugs in a University Pharmacy Benefit Plan
}

\author{
David P. Nau, PhD, RPh, CPHQ; Christina Chi, PharmD Student; Usha Mallya, PhD; and Duane M. Kirking, PhD
}

\begin{abstract}
BACKGROUND: Utilization management tools (e.g., multitier copayment designs, prior authorization, step therapy, quantity limits) are commonly used to optimize the efficiency and appropriateness of drug therapy. However, these tools may also lead to unfavorable humanistic outcomes, including confusion or annoyance for patients. There is also some concern about whether these tools, along with the cost-sharing burden for medications, may cause patients to discontinue using their medications as well as lead to dissatisfaction with pharmacy benefits. Although anecdotal evidence can be collected from customer complaints, few studies have systematically examined the extent to which prescription drug plan enrollees experience difficulties in obtaining medications and whether these difficulties are associated with their satisfaction with the drug plan.
\end{abstract}

OBJECTIVES: To determine from a member satisfaction survey (1) perception of difficulties experienced by drug plan members when they tried to obtain prescription medications, (2) whether some segments of members experienced more difficulties, and (3) whether self-reported difficulties in acquiring medications were associated with member satisfaction.

METHODS: The analyses were based on a cross-sectional survey using a stratified sample of drug plan members. Four thousand employees or retirees who used the University of Michigan prescription drug plan were sent a survey in 2005 to ascertain their satisfaction with the drug plan as well as their experiences with the plan. Specifically, the analyses focused on how frequently the patients experienced difficulties in obtaining medications because of costs or drug use management interventions (e.g., prior authorization, step therapy). Logistic regression analyses examined the relationship of copayment changes and drug use management interventions on patients' satisfaction with the drug plan.

RESULTS: Surveys were returned by 2,061 of the potential 3,667 eligible subjects with valid addresses ( $56.2 \%$ response rate). An overwhelming majority $(83.7 \%)$ of respondents were satisfied with the pharmacy benefit$17.6 \%$ reported being somewhat satisfied, $46.5 \%$ were satisfied, and $19.6 \%$ were very satisfied. Approximately $25 \%$ of drug plan members reported at least 1 difficulty in obtaining medication during the preceding year, including $11.4 \%$ who reported difficulties related to prior authorization or step therapy; only $2.0 \%$ reported that they couldn't afford their medication, and only $1.3 \%$ reported difficulty in paying the combined cost of their medications. Current employees were more likely to report difficulties than were retirees $(30.7 \%$ vs. $19.1 \%$; chi-square $=34.8 ; P<0.01$ ), and users of the mail-service pharmacy were somewhat more likely to experience difficulties than users of community pharmacies $(29.1 \%$ vs. $22.9 \%$; chi-square $=9.92 ; P<0.01)$. The logistic regression analyses revealed that having difficulty obtaining medications (odds ratio $[\mathrm{OR}]=0.27 ; 95 \%$ confidence interval $[\mathrm{CI}], 0.20-0.35$ ) and experiencing a copayment increase $(\mathrm{OR}=0.62 ; 95 \% \mathrm{Cl}, 0.48-0.81)$ were associated with a lower odds of member satisfaction. However, a high percentage of members were satisfied despite any difficulties or copayment changes: $66.9 \%$ for self-reported difficulty in obtaining medications compared with $89.7 \%$ (chi-square $=145.4, P<0.01$ ) and $78.6 \%$ for self-reported copayment increase compared with $87.9 \%$ (chi-square $=30.2, P<0.01$ ).

CONCLUSION: Survey respondents were highly satisfied with their pharmacy benefits despite drug use management interventions in this pharmacy benefit plan. Respondents who reported a copayment increase or difficulty in obtaining medication were less likely to be satisfied with the drug plan.
KEYWORDS: Member satisfaction, Drug benefit, Access

J Manag Care Pharm. 2007;13(2):135-41

A s prescription drug expenditures have risen in recent years, so have the efforts of managed care organizations to control the use of prescription drugs. Many drug plans have increased their use of utilization management tools such as multitiered copayments, prior authorization, quantity limits, and step therapy. ${ }^{1}$ These tools can be effective at shaping the utilization pattern for medications; however, they may also create difficulties for patients in obtaining needed medications. Although studies have examined the impact of specific drug use policies on satisfaction, ${ }^{2-4}$ few reports exist of how a broad range of difficulties experienced by prescription drug plan members may affect satisfaction.

In one of the few reports on the relationship of drug plan attributes and patient satisfaction, Desselle (2000) conducted interviews with 30 patrons of community pharmacies and had them identify the most important attributes of their drug plans. ${ }^{5}$ The patrons selected the items related to coverage restrictions as being the most important determinants of their satisfaction. The items in a resulting interval-level scale for satisfaction were then weighted, with the highest weights assigned to the "coverage limitations" items. A related study by Desselle (2001) used this weighted scale and found that drug plan members who perceived their drug coverage as being limited were less likely to be satisfied with their drug plans. ${ }^{6}$ However, since Desselle's multi-item satisfaction measure was most heavily weighted

\section{Authors}

DAVID P. NAU, PhD, RPh, CPHQ, is an associate professor, College of Pharmacy, University of Kentucky, Lexington; CHRISTINA CHI, is a PharmD student, University of Michigan, Ann Arbor; USHA MALLYA, PhD, is manager, Global Health Economics \& Outcomes Research, East Hanover, New Jersey; DUANE M. KIRKING, PhD, is a professor and director, Center for Medication Use Policy \& Economics, University of Michigan, Ann Arbor. (At the time of this study, Nau and Mallya were employed by the University of Michigan)

AUTHOR CORRESPONDENCE: David P. Nau, PhD, RPh, CPHQ, Associate Professor, College of Pharmacy, University of Kentucky, 725 Rose St., Lexington, KY 40536-0082. Tel: (859) 257-4523; Fax: (859) 257-6873; E-mail: dnau2@email.uky.edu

Copyright $\odot$ 2007, Academy of Managed Care Pharmacy. All rights reserved. 


\begin{tabular}{l|l|l}
\hline \multicolumn{2}{c}{ TAB LE 1) } & \multicolumn{1}{c}{$\begin{array}{l}\text { Examples of Drug Use } \\
\text { Management Interventions }\end{array}$} \\
\hline Strategy & Product & Specifics \\
\hline Quantity limit & Sildenafil & $\begin{array}{l}\text { Quantity limited to } \\
6 \text { units per month }\end{array}$ \\
\hline Dose optimization & Donepezil & $\begin{array}{l}\text { Must use 10-mg tablet } \\
\text { for 10-mg dose (i.e., 2 x } \\
\text { 5-mg tablets not allowed) }\end{array}$ \\
\hline Step therapy & COX-2 inhibitors & $\begin{array}{l}\text { Patients younger than 70 } \\
\text { years must have tried at } \\
\text { least 2 generic NSAIDs } \\
\text { before COX-2 drug }\end{array}$ \\
\hline Prior authorization & Methylphenidate & $\begin{array}{l}\text { Prior authorization } \\
\text { required if patient is } \\
\text { aged 18 years and has } \\
\text { not previously received } \\
\text { drug therapy for } \\
\text { attention-deficit/ } \\
\text { hyperactivity disorder }\end{array}$ \\
\hline & &
\end{tabular}

COX-2 = cyclooxygenase-2; NSAIDs= nonsteroidal anti-inflammatory drugs.

toward items related to coverage limitations, it is not surprising that it was associated with perceived coverage limitations.

A more recent study by Motheral and Heinle (2004) identified numerous determinants of health plan members' satisfaction with prescription drug benefits. ${ }^{7}$ They found that higher copayments, coinsurance, closed formularies, intensive managed care, large health care premiums, a recent increase in copayments, and a recent denial of coverage were associated with lower satisfaction with the drug plan. Although this study was limited by a low response rate (27\%), it does suggest that drug plan policies may be related to patients' satisfaction. However, because the respondents came from a multitude of plans with differing structures and policies, it was not possible for the authors to fully sort out the various types of coverage restrictions and their potentially different effects on satisfaction.

Although the aforementioned studies indicate a potential relationship between policies for controlling drug use and enrollees' satisfaction with a drug plan, we do not know the extent to which members within a typical drug plan experience difficulties in obtaining their medications. It is also not clear how various types of difficulties in obtaining medications relate to member satisfaction for a population in a single drug plan (thereby controlling for the potential confounding that stems from differing premiums and copayment structures). Thus, the objectives of this study were to (1) identify the difficulties experienced by drug plan members when they tried to obtain prescription medications, (2) determine whether some segments of members experienced more difficulties, and (3) determine whether difficulties in acquiring medications were associated with enrollee satisfaction.

\section{Methods}

\section{Description of the Drug Plan}

The University of Michigan (UM) drug plan is a carve-out model in which all employees and retirees of the university, along with eligible dependents, are included in 1 drug plan regardless of their chosen health insurance plan. A mail-services pharmacy option is available to all members as well as an extensive network of community pharmacies. An open formulary is maintained with a 3-tier copayment design and preferred drug list (PDL). This benefit design is supplemented by drug use management interventions such as step therapy, prior authorization, quantity limits, and dose optimization (Table 1). All members have the 3-tier copayment design except for a small number of unionized employees who have a 2-tier copayment and a small number of retirees who have a coinsurance benefit design. The 3-tier copayment amounts were $\$ 7, \$ 14$, and $\$ 24$ for tiers 1,2 , and 3 , respectively.

Members could obtain a 90-day supply of medication from a community pharmacy (for 3 copays) or from a mail-service pharmacy (for 2 copays). Tier 1 in the formulary included all generic drugs. Tier 2 included brand-name drugs that were considered by the plan to be more cost effective than other drugs within each class (i.e., preferred brand drugs), and tier 3 included brand-name products that were not selected for tier 2 (i.e., nonpreferred drugs). The copayment amounts for each tier did not change from 2003 through 2005, but a small number of drugs changed copayment tiers as new drugs became available or as new evidence regarding the cost-effectiveness or safety of the products became available. For example, Neurontin was removed from the PDL to nonpreferred (tier-3 copayment) when a generic equivalent (gabapentin) became available.

A pharmacy benefits manager provides claims processing and other benefit management services but with active involvement of a UM committee that determines the policies for drug use management and selects products for the PDL.

\section{Survey Sample}

The target population for the survey was the users of the UM prescription drug plan (approximately 28,500 persons per calendar quarter). A stratified sample of 4,000 subjects was selected from a list of UM employees and retirees who had more than 1 pharmacy claim for a prescription drug in 2004. A stratified sample was used to ensure adequate representation of key groups of drug plan users, and the sample size was chosen to maintain a sampling error of less than 3\% with $\alpha=95 \%$ for each stratum. The sample size for each stratum was (1) retirees using only community pharmacies ( $n=1,000)$, (2) retirees using the mail-service pharmacy $(n=500)$, (3) current employees using only community pharmacies $(n=1,500)$, and (4) current employees using the mail-service pharmacy $(n=1,000)$. Employees on longterm disability were included in the last 2 categories, depending on their source of medication procurement. Mail-service phar- 


\section{TABLE 2 Beneficiary Survey Instrument (Excerpted)}

1. Overall, how satisfied are you with the University of Michigan prescription drug plan?

$\square$ Very Dissatisfied $\square$ Dissatisfied $\square$ Somewhat Dissatisfied $\square$ Somewhat Satisfied $\square$ Satisfied $\square$ Very Satisfied

2. How would you rate the quality of the UM prescription drug plan as compared to other prescription drug plans you have heard about (e.g., from other employers)?

a A lot worse $\square$ A little worse $\square$ About the same $\square$ A little better $\square$ A lot better

5. In the past year, have you had difficulty obtaining medication that your doctor prescribed for you?

口 Yes $\square$ No

If Yes, what type of difficulty was encountered? (Please check all that apply)

- The pharmacy did not have the medication(s).

The mail-service pharmacy did not get the medication to me by the day that I needed it.

I was told that I had to try another medication before I could get the one that my doctor prescribed.

I could not afford the cost of a specific medication.

The combined cost of all my medications made it difficult for me to get all of them.

○ Other

6. During the past year, did the copay increase for at least one of your medications (i.e., were you asked to pay more for a medication than you previously paid)?

$\square$ Yes $\square$ No

If Yes, what did you do?

Kept taking the same medication and paid the higher copay.

- Switched to a different medication (either a brand or generic drug).

- Stopped taking the medication and did not start taking a new one.

macy users were oversampled to ensure that their perspective was considered adequately and to permit valid comparisons between the responses from users of the mail-service pharmacy compared with users of community pharmacies.

For sampling purposes, members were included in the mailservice category if they had received more than 1 medication from the mail-service provider. Within the survey, the subjects were asked about their pattern of pharmacy patronage. Those who indicated that they "mostly" or "always" used the mail-service provider were categorized as mail-service users for the analyses.

\section{Measures}

\section{Satisfaction}

Satisfaction was assessed on a 6-point Likert scale with options that ranged from "very dissatisfied" to "very satisfied" (Table 2). Because the resulting distribution was highly skewed toward greater satisfaction, a categorical variable was created wherein responses were coded as 1 for subjects who were "somewhat satisfied," "satisfied," or "very satisfied," and all other responses were coded as 0 .
In order to evaluate patients' perception on their drug plan in comparison with other plans, the subjects were asked the following question: "How would you rate the quality of the UM prescription drug plan as compared to other prescription drug plans you have heard about (e.g., from other employers)?" The 5 response options ranged from "A lot better" to "A lot worse."

\section{Difficulties in Obtaining Medications}

Subjects were asked if, during the past year, they had difficulty obtaining medications that their doctor had prescribed for them. Those who responded affirmatively were asked to indicate the type of difficulty they encountered. A list of common problems was provided with instructions to check the box next to all those encountered. An option of "other" was also provided along with instructions to describe the other types of problems in acquiring medications. If patients checked "other" but described a problem that was clearly related to one of the predefined categories, the "other" response was combined with that category. 


\section{TABLE 3 Survey Respondent Characteristics}

\begin{tabular}{|c|c|c|}
\hline Characteristic $(\mathrm{N}=2,061)$ & Number & $\%$ \\
\hline \multicolumn{3}{|l|}{ Employment status } \\
\hline Current faculty & 182 & 9.3 \\
\hline Current staff & 793 & 40.7 \\
\hline Retired faculty & 234 & 12.0 \\
\hline Retired staff & 574 & 29.5 \\
\hline Spouse of current employee & 25 & 1.3 \\
\hline Spouse of retiree & 94 & 4.8 \\
\hline Long-term disability & 47 & 2.4 \\
\hline Missing data for beneficiary status & 112 & \\
\hline \multicolumn{3}{|l|}{ Years at UM (current employees) } \\
\hline$<2$ years & 64 & 6.4 \\
\hline $2-5$ years & 238 & 23.8 \\
\hline $6-10$ years & 204 & 20.4 \\
\hline $11-20$ years & 262 & 26.2 \\
\hline$>20$ years & 232 & 23.2 \\
\hline \multicolumn{3}{|l|}{ Pharmacy services } \\
\hline Community & 1,122 & 56.4 \\
\hline Mail* & 865 & 43.6 \\
\hline Missing data & 74 & \\
\hline \multicolumn{3}{|c|}{ Number of prescriptions in last 3 months } \\
\hline 0 & 42 & 2.1 \\
\hline $1-6$ & 1,100 & 55.8 \\
\hline $7-12$ & 499 & 25.3 \\
\hline $13-24$ & 231 & 11.7 \\
\hline$\geq 25$ & 101 & 5.1 \\
\hline Missing data & 88 & \\
\hline \multicolumn{3}{|c|}{$\begin{array}{l}\text { * Classified as mail-service pharmacy user if response was "mostly" or "always" } \\
\text { obtained medication from the mail-service pharmacy. } \\
\text { UM=University of Michigan. }\end{array}$} \\
\hline
\end{tabular}

\section{TABLE 4 Frequency of Reported Difficulties} in Obtaining Medications $(\mathrm{N}=2,061)^{*}$

\begin{tabular}{l|r|r}
\hline Difficulty & $\mathbf{n}$ & $\%$ \\
\hline Difficulties related to prior authorization or step therapy & 234 & 11.4 \\
\hline The pharmacy did not have the medication & 96 & 4.7 \\
\hline Delay in delivery from mail-service pharmacy & 75 & 3.6 \\
\hline Patient could not afford the cost of a specific medication & 42 & 2.0 \\
\hline $\begin{array}{l}\text { The combined cost of all medications made it difficult } \\
\text { for patient to get all of them }\end{array}$ & 26 & 1.3 \\
\hline Other difficulties & 38 & 1.8 \\
\hline * Table 2, survey item $\# 5$. & & \\
\hline
\end{tabular}

\section{Survey Procedures}

A written questionnaire and cover letter were mailed to the subjects in early May 2005 (Table 2). A reminder postcard was sent 1 week after the questionnaire. In late June, non-respondents were mailed a second questionnaire and cover letter. Data collection was discontinued on July 29, 2005. Of the 4,000 surveys mailed, 333 were undeliverable because of incorrect addresses or because the subject had died or was physically unable to complete the survey. Thus, there were presumed to be 3,667 eligible subjects.

\section{Analysis}

Descriptive statistics were calculated for all the variables. To estimate the extent of response bias, the satisfaction ratings of the early responders were compared with the late responders (late responders are considered to be most similar to nonresponders) using an independent samples $t$ test $(\alpha=95 \%)$.

The association of satisfaction and difficulties in obtaining medications was first assessed using a chi-square test. Additionally, a multivariate logistic regression analysis was conducted with satisfaction as the dependent variable. Independent variables included "difficulty in obtaining medication," copayment increase, gender, faculty compared with staff, employee compared with retiree, and mail-service compared with community pharmacy patronage. All analyses were conducted using SPSS software, v. 14.0 .

\section{Results}

\section{Respondents}

Surveys were returned by 2,061 of the potential 3,667 eligible subjects (56.2\% response rate). The satisfaction ratings for early and late responders were nearly identical. Additionally, the response rates for the 4 strata (i.e., retirees using only community pharmacies, retirees using the mail-service pharmacy, current employees using only community pharmacies, and current employees using the mail-service pharmacy) were similar, and the age and gender distributions of the respondents were similar to the original sample. Thus, there did not appear to be a substantial response bias.

Table 3 shows the characteristics of the respondents. Retirees were more likely to fill more than 12 prescriptions in the last 3 months ( $21.6 \%$ vs. $12.8 \%$, chi-square $=49.31, P<0.01)$; however, there was no difference in use based on faculty status or source of medications (mail-service vs. community pharmacy).

\section{Difficulties in Obtaining Medications}

Overall, 511 (24.8\%) of respondents indicated that during the past year, they had difficulty obtaining prescription medications. Current employees were more likely to report difficulties than were retirees $(30.7 \%$ vs. $19.1 \%$, chi-square $=34.8, P<0.01)$ and users of the mail-service pharmacy were somewhat more likely to experience difficulties than users of community pharmacies $(29.1 \%$ vs. $22.9 \%$, chi-square $=9.92, P<0.01)$. There were no 
differences between faculty and nonfaculty employees in experiencing this difficulty.

The most common types of difficulty reported were related to prior authorization or step therapy (Table 4). Other common difficulties included delivery problems from the mail-service pharmacy or the pharmacy not having the medication. Costrelated difficulties were reported by only $3.3 \%$ of the 2,061 respondents.

Cost-related difficulties could be exacerbated by increases in copayments for medications. The cost (e.g., copayment) for at least 1 of the medications for 915 of the respondents (44.4\%) had increased during the past year (data not reported in tables). Nearly $85 \%$ of those who had experienced an increase in copayment indicated that they continued to take the same medication and paid the higher cost, while $11 \%$ switched to a different medication with a lower copayment. Only 40 people $(4.4 \%$ of those who experienced a copayment increase) responded that they stopped taking the medication and did not start taking a new one. Only $5.1 \%$ of respondents who experienced a copayment increase also indicated that the cost of their medications made it difficult for them to obtain their medications.

\section{Satisfaction With the Pharmacy Benefit Plan}

The vast majority of respondents (83.7\%) indicated that they were "somewhat satisfied," "satisfied," or "very satisfied" with the university's pharmacy benefit plan (Table 5, survey item \#1 in Table 2).

When asked to rate the quality of the university's pharmacy benefit plan compared with other pharmacy plans that they had heard about, $47.9 \%$ of respondents rated the university's drug plan as better than others. Another 34.8\% believed that the university's plan was about the same as other plans, and $17.8 \%$ believed that the university's drug plan was worse than other drug plans.

There were no significant differences in satisfaction based on employment status (faculty vs. nonfaculty employees), source of medications (mail-service vs. community pharmacy), or volume of prescriptions purchased. However, retirees were more likely to be satisfied with the drug plan than current employees $(87.1 \%$ vs. $81.0 \%$, chi-square $=13.9, P<0.01)$.

\section{Self-Reported Difficulty in Obtaining Medication and Satisfaction}

Respondents who experienced an increase in copayment were less likely to be satisfied with the drug plan $(78.6 \%$ vs. $87.9 \%$, chi-square $=30.2, P<0.01$ ). Respondents who experienced difficulties in obtaining medications were less likely to be satisfied with the drug plan $(66.9 \%$ vs. $89.7 \%$, chi-square $=145.4, P<0.01)$.

When multivariate regression analyses were conducted to control for gender, prescription volume, employee versus retiree, mail-service versus community, and faculty versus staff, the patients' experiences with "difficulty in obtaining medications"
TABLE 5 Satisfaction With the Drug Plan $(N=2,061)^{*}$

\begin{tabular}{l|c|c}
\hline Response & $\mathbf{n}$ & $\%$ \\
\hline Very satisfied & 404 & 19.6 \\
\hline Satisfied & 958 & 46.5 \\
\hline Somewhat satisfied & 363 & 17.6 \\
\hline Somewhat dissatisfied & 148 & 7.2 \\
\hline Dissatisfied & 86 & 4.2 \\
\hline Very dissatisfied & 67 & 3.3 \\
\hline Missing data & 35 & 1.6 \\
\hline
\end{tabular}

* Table 2, survey item \#1.

and copayment increases were associated with the odds of satisfaction (Table 6). Thus, members who experienced 1 or more difficulties in obtaining medication and members who experienced an increase in copayment were less likely to be satisfied with the drug plan.

\section{Discussion}

Utilization management tools (e.g., multitier copayment designs, prior authorization, step therapy, quantity limits) are commonly used to optimize the efficiency and appropriateness of drug therapy. However, these tools may also lead to unfavorable humanistic outcomes in member confusion, inconvenience, and annoyance. The need to manage use of medications must be weighed against the potentially negative impact of these tools on member and provider satisfaction.

Nearly $25 \%$ of respondents to this survey reported some difficulty in obtaining a prescription medication within the past year. The most commonly reported problems pertained to step therapy or prior authorization, while very few respondents (3.3\%) reported cost-related difficulties. This is not surprising since the UM prescription drug plan has an open formulary but employs interventions such as step therapy, prior authorization, and a 3-tier copayment drug benefit design to promote appropriate drug use. Most members of the drug plan have a 3-tier copayment structure with copayments of $\$ 7, \$ 14$, and $\$ 24$ for generic, preferred brand, and nonpreferred brand drugs. These copayment amounts have remained the same since 2003 and are lower than recent national benchmarks. ${ }^{8}$ The relatively low copayments apparently did not create access difficulties for the majority of the members.

A surprising proportion of respondents (44.4\%) indicated that the cost (e.g., copayment) for at least 1 of their medications had increased during the past year, despite the copayment amounts for the 3-tier design that did not change from 2003 through 2005. However, several products changed copayment tier from May 2004 through April 2005, the 12 months before the survey. The change in copayment tier that occurred was typically a 


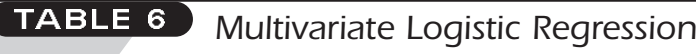 for Explaining Member Satisfaction}

\begin{tabular}{|c|c|c|}
\hline Independent Variables & Odds Ratio & $95 \% \mathrm{CI}$ \\
\hline \multicolumn{3}{|l|}{ Variables of interest } \\
\hline \multicolumn{3}{|l|}{ Difficulty in obtaining medication? } \\
\hline Yes & 0.27 & $(0.20-0.35)^{*}$ \\
\hline No & 1.00 & \\
\hline \multicolumn{3}{|l|}{ Copayment increase? } \\
\hline Yes & 0.62 & $(0.48-0.81)^{*}$ \\
\hline No & 1.00 & \\
\hline \multicolumn{3}{|l|}{ Covariates } \\
\hline \multicolumn{3}{|l|}{ Employment } \\
\hline Retired & 1.41 & $(1.07-1.85)^{*}$ \\
\hline Current & 1.00 & \\
\hline \multicolumn{3}{|l|}{ Status } \\
\hline Faculty & 0.96 & $(0.69-1.85)$ \\
\hline Nonfaculty & 1.00 & \\
\hline \multicolumn{3}{|l|}{ Source of medications } \\
\hline Mail & 1.12 & $(0.87-1.46)$ \\
\hline Community & 1.00 & \\
\hline \multicolumn{3}{|l|}{ Rx use (in past 3 months) } \\
\hline$>12 \mathrm{Rx}$ & 0.90 & $(0.69-1.17)$ \\
\hline$\leq 12 \mathrm{Rx}$ & 1.00 & \\
\hline \multicolumn{3}{|l|}{ Gender } \\
\hline Male & 0.99 & $(0.81-1.21)$ \\
\hline Female & 1.00 & \\
\hline
\end{tabular}

PDL-listed product (e.g., Diflucan, Glucovance, Neurotin, Wellbutrin SR) that moved from tier-2 copayment to tier-3 copayment when a generic product became available. A small percentage of retirees had a coinsurance benefit for prescriptions, wherein they paid $20 \%$ of the cost of medications. Thus, price increases for these products may have led to an increase in coinsurance payment by the enrollee. Yet another potential influence on perceived copayment increases was a benefit change in September 2004 to allow enrollees to obtain a 90-day supply of medications at community pharmacies for the equivalent of 3 monthly copayments. Some individuals may have interpreted this change as an increase in their cost share. Consequently, there are several plausible scenarios in which enrollees could experience an actual, or perceived, increase in their cost share for medications.

Although few respondents indicated that cost made it difficult for them to obtain their medications, those respondents who experienced an increase in the cost of a medication during the past year were more likely to report a cost-related difficulty for obtaining medication. However, only $4.4 \%$ of respondents who experienced an increase in out-of-pocket cost indicated that they discontinued taking medication as a result of the increased cost.

The university drug plan was generally well regarded by its members; two thirds of respondents indicated full satisfaction with the plan and nearly one half of respondents rated the UM drug plan as better than competing plans. However, those members who experienced difficulties in obtaining their medications were less likely to be satisfied. This is consistent with the study by Motheral and Heinle (2004), who found that persons who experienced a coverage denial were less likely to be satisfied with the drug plan. ${ }^{7}$ This is also consistent with a study by Holdford and Carroll (2002), who found that product choice (i.e., a patient's insurance permits the pharmacy to dispense any medication that the doctor prescribes) was the most important attribute for consumers in choosing a drug plan. ${ }^{9}$

One uncertainty that has arisen from recent studies of consumer preferences for drug plan attributes and their satisfaction with drug plans is whether the strongest determinant of satisfaction is the member's level of out-of-pocket spending or the difficulty that a member encounters when trying to obtain medications (e.g., coverage denial). It is interesting that in the Motheral and Heinle study, the authors found that the variables most strongly associated with satisfaction in their logistic regression model were related to coverage denials or changes in copayment, whereas the average copayment amount was only weakly associated with satisfaction. ${ }^{7}$ However, when the subjects were asked to rate the most important feature of a drug benefit, the out-of-pocket costs were rated as the most important feature with the "list of drugs covered by the plan" as a distant second.

Out-of-pocket costs and coverage restrictions are both important to drug plan members. However, there are fundamental differences in how consumers encounter both of these potential barriers to medication acquisition. The copayment or coinsurance structure of the drug benefit design is often well publicized by the plan and is usually applicable to all drugs. Thus, consumers expect to pay a portion of the costs of the drug and are usually not surprised by the presence of a copayment (although they may be unhappy with the amount of the copayment for a nonpreferred brand drug, for example). Prior authorization or other restrictions are often not expected and thus may create dissatisfaction with the drug benefit. A change in the copayment for a drug may also not be expected; in the current study, members who experienced a copayment increase most likely were using a PDL-listed brand drug that moved to tier 3 when a generic equivalent drug became available. Numerous marketing studies have demonstrated how unpleasant surprises within a service encounter lead to dissatisfaction..$^{10,11}$

If member satisfaction is affected negatively by unexpected restrictions or changes to drug benefits, then one might expect that educating consumers about the rationale for the restriction 
or change may lessen the surprise or confusion involved with various drug plan policies. Although there is evidence that the dissemination of health plan information has a positive effect on patient satisfaction, ${ }^{12}$ the relationship of general knowledge about a plan and member satisfaction is predictably small. ${ }^{13,14}$ Furthermore, there appears to be no relationship between satisfaction and members' understanding of the details of a plan (e.g., copayment structure, drug use management strategies). ${ }^{14}$

\section{Limitations}

The first and foremost limitation of the current study was the absence of analysis of the relationship of actual drug use data with self-reported survey (satisfaction) data. Comparison of self-reported copayment increase to actual drug-use experience may have provided useful insight into the apparent overreporting of a drug copayment increase.

Second, member satisfaction was assessed by only a few survey questions that have face validity but have not otherwise been validated. We did not, for example, ask pharmacy benefit users about their perception of quantity limits or other use management interventions other than the 1 question about perceived difficulty in obtaining medication related to prior authorization or step therapy ("I was told that I had to try another medication before I could get the one that my doctor prescribed"; see survey item \#5, Table 2). Third, although there did not appear to be a substantial response bias, it is possible that the persons who responded had different opinions or experiences from nonrespondents. Fourth, the study sample was derived from only 1 drug plan, and these results may not be generalizable.

\section{Conclusion}

Patients who experienced a self-reported increase in the cost of their medication or who experienced self-reported difficulties in obtaining their prescribed medication were less likely to be satisfied with their drug plan. Further study is encouraged, particularly regarding the impact of educating consumers on drug plan policies and pharmacy benefit interventions that may affect access or member out-of-pocket cost.

\section{What is already known about this subject}

- Members of pharmacy benefit plans who perceive their drug coverage as being limited are less likely to be satisfied with their plans.

- It is not clear how various types of drug use management interventions relate to member satisfaction.

\section{What this study adds}

- Members were highly satisfied with their pharmacy benefit despite several drug use management interventions.

- Patients who reported an increase in the cost of their medication or difficulty in obtaining their medication were less likely to be satisfied with their pharmacy benefit plan.

\section{ACKNOWLEDGMENTS}

The authors acknowledge the assistance of Dawn Parsons and Keith Bruhnsen, University of Michigan Benefits Office, Ann Arbor, for their support in conducting the study. The comments of Suzan Kucukarslan, PhD, University of Michigan College of Pharmacy, Ann Arbor, on drafts of this article were also greatly appreciated.

\section{DISCLOSURES}

No outside funding supported this research. The authors disclose no potential bias or conflict of interest relating to this article. Author David P. Nau served as principal author of the study. Study concept and design were contributed by Nau, with input from authors Christina Chi and Duane M. Kirking. Data collection was primarily the work of Chi, with input from author Usha Mallya: data interpretation was primarily the work of Nau, with input from the coauthors. Writing of the manuscript and its revision were the work of Nau, with input from the coauthors.

\section{REFERENCES}

1. Mercer Health \& Benefits. Hot topics in health care: pharmacy benefits. Summary of results. Available at: http://wrg.mercerhr.com/content_print.asp? article_id=20066135\&ext=.PDF. Accessed May 4, 2006.

2. Cox ER, Henderson R, Motheral BR. Health plan member experience with point-of-service prescription step therapy. J Manag Care Pharm. 2004;10(4): 291-98. Available at: http://www.amcp.org/data/jmcp/Research-291-298.pdf. Accessed January 22, 2007

3. Motheral BR, Henderson R, Cox ER. Plan-sponsor savings and member experience with point-of-service prescription step therapy. Am J Manag Care. 2004; 10:457-64

4. Nair KV, Ganther JM, Valuck RJ, McCollum MM, Lewis SJ. Impact of multitiered pharmacy benefits on attitudes of plan members with chronic disease states. J Manag Care Pharm. 2002;8:477-91. Available at: http://www.amcp.org/ data/jmcp/Research-477-491.pdf. Accessed January 22, 2007.

5. Desselle S. Development of an interval-level scale to assess consumer satisfaction with prescription drug coverage. J Manag Care Pharm. 2000;6(3):22531

6. Desselle S. Determinants of satisfaction with prescription drug plans. Am J Health Syst Pharm. 2001;58:1110-19.

7. Motheral BR, Heinle SM. Predictors of satisfaction of health plan members with prescription drug benefits. Am J Health Syst Pharm. 2004;61:1007-14.

8. Kaiser Family Foundation (KFF) and the Health Research and Educational Trust (HRET). 2005 employer health benefits annual survey. Available at: http://www.kff.org/insurance/7315/sections/upload/7316.pdf. Accessed May 4, 2006.

9. Holdford D, Carroll NV. Consumer preferences for types of cost containment in prescription drug programs. J Manag Care Pharm. 2002;8:192-98. Available at: http://www.amcp.org/data/jmcp/Research-192-198.pdf. Accessed January 22, 2007.

10. VanHamme J. The link between surprise and satisfaction: an exploratory research on how best to measure surprise. J Market Manag. 2000;16:565-82.

11. VanHamme J, Snelders D. The role of surprise in satisfaction judgment. J Consumer Satisfaction, Dissatisfaction Complaining Behav. 2001;14:27-45.

12. David K, Schoen C. Assuring quality, information, and choice in managed care. Inquiry. 1998;35:104-14.

13. Tucker JL. Patients' knowledge of health plan coverage and satisfaction with care. Am J Manag Care. 2001;7:453-59.

14. Olson BM, Malone DC, Zachary WM, Coons SJ. Consumer understanding and satisfaction associated with a 3-tier prescription drug benefit. J Manag Care Pharm. 2005;11(6):480-92. Available at: http://www.amcp.org/data/jmcp/ 4.pdf. Accessed January 22, 2007. 